Journal of Engineering and Applied Sciences 14 (Special Issue 4): 7431-7436, 2019

ISSN: 1816-949X

(C) Medwell Journals, 2019

\title{
Intrinsic Value in Environmental Species Vis-a-Vis Igbo Cultural Technology
}

\author{
${ }^{1}$ George Ohabuenyi Abah, ${ }^{1}$ Joseph Nnaemeka Chukwuma, ${ }^{1}$ Uche Miriam Okoye, \\ ${ }^{1}$ Francis Okechukwu Ekwueme, ${ }^{2} \mathrm{Christian}$ Onuorah Agbo, ${ }^{1} \mathrm{Charles}$ Kenechukwu Okoro, \\ ${ }^{1}$ Chioma Winifred Ezeanya, ${ }^{2}$ Gabriel Chukwuebuka Otegbulu and ${ }^{1} \mathrm{John}$ Obiora Anichebe \\ ${ }^{1}$ Department of Philosophy, \\ ${ }^{2}$ School of General Studies, Humanities Unit, University of Nigeria, Nsukka, \\ PMB 410001, Enugu State, Nigeria \\ joseph.chukwuma@unn.edu.ng, +234803772330
}

\begin{abstract}
For some centuries past, philosophy had a sustained emphasis on human beings without a tincture of consideration stretched to nonhuman nature. This gave birth to anthropocentrism, especially, in the West where man was conceived as the "measure of all things". Within these centuries, man was not only seen as the centre of the universe but the only being in nature whose moral value deserves consideration. Other species in the environment were only considered to be instrumental to human ends.In contrast to the position of this school of thought, the Igbo culture posits that the environment is replete with intrinsic value in varied species. For this cultural group, it takes a closer study of different species in nature to arrive at a discovery of an autonomous intrinsic values in environmental species. These are activities that inhere in both living and non-living things independent of human valuation. Hence, an instrumental valuation of nature is not sufficient until an intrinsic valuation is considered. In short, the Igbos show case this sense in their local technologies such as rain-making, varied herbal healings not excluding snake-bites, scorpion-stings, fracture or bone-healing and even poisons to which they recline on what the environment gives them for solutions or interventions. In these cases, they project the values that are inherent in herbs, trees, animals, animate and inanimate components of the environment as the source of their discoveries and advancements. Aside the visible components of the environment are also, the invisible beings that assist the discovery of some of these useful components of the environment which they call their ancestors. Suffice it to say that, the extent to which Igbo technologies manifest good results is the extent to which the Igbos relate with their material and immaterial environments. This research, therefore, studies the theory of intrinsic value in environmental species to explore the assistances they offer the Igbos in one of their local technologies namely, rain-making. The result of this study shows that if, we are to value the environment intrinsically and acknowledge its immaterial components, rich values from the environment will sufficiently assist our technologies for our well-being.
\end{abstract}

Key words: Intrinsic value, environmental species, Igbo culture, cultural technology, components, theory of intrinsic

\section{INTRODUCTION}

Environmental ethics is moral philosophy concerning nonhuman nature. All the way from Socrates to Sartre, ethics heaps her concern only on humans. The anthropocentric texture of the Western philosophy is the resultant effect of this sustained emphasis on humans. In the words of Keller (2010), "environmental ethics constitutes critiques of anthropocentrism some positive, others negative. In the context of the history of the Western intellectual tradition, this critique is both revolutionary and inevitable. Environmental ethics is revolutionary in departing from a bi-millennial tradition in moral philosophy that has identified humans exclusively as the subject-matter of ethics. Environmental ethics is inevitable in that this assumption could not be accepted as an article of faith in perpetuity. Environmental ethics concerns how humans as moral agents should best live their lives in their Earthly home. It expresses some deep studies on humans, the environment and a possible relationship between the two.

The Igbo culture attaches much value to the environment. Apart from finding himself in an environment consequent upon his creation, the Igbos

Corresponding Author: Joseph Nnaemeka Chukwuma, Department of Philosophy, University of Nigeria, Nsukka, PMB 410001, Enugu State, Nigeria, joseph.chukwuma@unn.edu.ng, +234803772330 
believes that their environment contributes much in making them. Their interactions with their environment lead them into much discoveries of, so many values attached to things around them-material and nonmaterial. Some trees, mountains, rivers and so on are not only valued but sometimes worshipped as they form sources of wonder in the Igbo cultural environment. It is in this extreme value-ability culminating in worship of the environment that the Igbos attach themselves to the ancestors who they believe possess the same environment (albeit invisible) for co-operation and assistance. Through this attachment to the environment, so many discoveries are made such that some leaves, roots, herbs, stones etc. with some communications with the ancestors are discovered to be sources of healing and other manipulations of nature like rainmaking. This study, therefore is a specific concern on how much the intrinsic values in an environmental species assist rainmaking in Igbo cultural technology.

Significance statement: In the Igbo cultural outlook, apart from its material possessions, the Earth is also, imbued with immaterial existence. The Earth is an enabling environment for the relationship between the living and the dead in the Igbo culture. The Earth is the meeting point between the living and the dead ancestors and the latter feature for assistance, direction and protection of the former. Exposing further details about the Earth, Nwala (1985) said that, the Earth "is regarded as the abode of man, animals, birds, plants and a host of other created beings. It is the scene, in most Igbo folktales and mythologies where gods and men interact." This submission made by Nwala (1985) testifies to the material and the immaterial contents of the Earth. Hence, the position of man on Earth is a relational state with both the material and the immaterial beings or entities. Hence, the Earth is a place to value because of the endowments in it that aid the lives of the living and the dead. We have seen from the above, that man is face to face with values inherent in the environmental species. These values, apart from being instrumental to man wherein man supports his life from his relationship with them are values that intrinsically inhere in them. Meanwhile, man being a superior subject to all the other species, relates with them for instrumental reasons and intrinsic reasons. It is instrumental when man's relationship with them is for his consumption and satisfaction. It is intrinsic when man simply appreciates these species for what they are and not for what they offer him. From here then, we shall take off to establish how man in the Igbo cultural milieu has improved in his technology by his association with some of these species. Our particular concern in all the technologies in the Igbo cultural setting is rainmaking. The objective of the present study is to examine the theory of intrinsic value in the environmental species vis-a-vis the Igbo technology in rainmaking.

\section{MATERIALS AND METHODS}

The study used a qualitative research design. The specific methods used were historical, expository and critical. The historical method was used to trace philosophers from history who projected their opinions on environmental ethics as well as the Igbo cultural milieu. The expository method was used to dissect the intrinsic values of the environment to understand in details the assistance it offers the Igbo cultural technology specifically in rainmaking. Finally, it is critical because the method weighed the Igbo rainmaking technology on a logical scale to know how meaningful and convincing this discovery was and the benefits therein.

\section{RESULTS AND DISCUSSION}

Intrinsic value in environmental species: The question of "value" in the philosophical environment is a hair-splitting one. Axiology is the study of values. The word "axiology" comes from two Greek words axios (of value) and logos (theory). The problem of where to position value either in the object or in the subject or in the relational both has raised, so many schools of thought who in their divergent opinions make some reasonable claims. Environmental metaethical objectivism (or metaethical realism) holds that nonhuman natural objects are valuable independently of human consciousness (that is intrinsically and objectively). Environmental metaethical subjectivism (or metaethical relativism) on the contrary, holds that nonhuman natural objects are valuable only insofar as humans desire them (that is extrinsically and subjectively). Meanwhile a third school of thought, the environmental relationists, opine that value does neither reside exclusively in the object nor in the subject but in the relationship between the subject and the object. According to Njoku (2006), "there are things that are of value independent of the judgement of the other person or institution. Human persons are of value on their own right conferred on them by the Creator, there are certain things, we endow values given the use we have come to make of them. We also create values in our interaction with persons and things. Values, therefore, emerge as process of resolution or harmonization of conflicts within a social environment or situation."

Having seen the divergent opinions about where the residence of value that is whether in the subject in the 
object or in the relational both, we can now attempt to explore some intrinsic values in species replete in our environment to see, if, we can stretch value beyond man to other species in human environment. Our observational take-off is from man himself as part of the environment.

Man: Humans not only value but are also valued for the endowments in them. Descartes's cogito is suggestive that humans are capable of valuing things in nature. Man, consequent upon his endowments can value nature both instrumentally and intrinsically. For Windelband, "value is never found in the object itself as a property. It consists in a relation to an appreciating mind. Take away will and feeling and there is no such thing as value." To this, Norton (1991) concludes that, "moralists among environmental ethicists have erred in looking for a value in the living things that is independent of human valuing". They have therefore, forgotten a most elementary point about valuing anything. Valuing always occurs from the viewpoint of a conscious valuer. Only the humans are valuing agents." The intrinsic glories of man is almost in line with Protagora's idea that ' $m$ an is the measure of all thing's. Apparently, it exists within the capacities of man to measure values in things both subjectively and objectively. Hence, man is valuable.

In the Igbo setting, it is a popular belief that all human beings are not ontologically equal. Some possess certain attributes, powers and influences over and above others. These earn them greater respect, honour and even fear. In this context, a rainmaker in the Igbo cultural background is assumed to possess some supernatural powers or some quality values to cause the rain to fall or not to fall. Perhaps, consequent upon this intrinsic value in the rainmaker, he relates and communicates with the immaterial entities of his environment that assist him in his art of rainmaking. Therefore, it could be established from the foregoing that man generally possesses intrinsic values in him that assist him to value things in nature. But as it concerns this research, the rainmakers particularly are endowed with some exceptional or uncommon intrinsic values that assist them make or mar rainfalls.

Animals: There is a practical demonstration of an autonomous intrinsic value in animals as we readily admire in the activities of wildlife which not only are born free but maintain their independent existence. These activities are show cased in the way they hanker after their shelters, seek a safe place for habitation, procreate, tender their young, hide from suspected dangers, express hunger, demonstrate lassitude etc. When injured, animals lick their wounds for healing. In the face of these activities, it seems absurd to say that animals are only valued when the subject-valuer is there. This is because these activities are in no way influenced by man (as a subject) for their performance. Hence, it is the opinion of many ethicists that animals do not make humans the measure of all things at all. And to give their stand a sound landing, they expose their discoveries in the activities of a mother bath as an example. According to them, a mother free-tail bat can in total darkness, wend her way out to catch 500-1000 insects each hour on the wing and return to find and nurse her own young. This activity of the mother bath proves that it values not only the pup but also the insects caught for food.

Animals occupy an important place in Igbo traditional ontological thought. Apart from their myths and folklores that are replete with beliefs that animals have souls and spirits like men, the Igbos believe too that animals can see spirits. No wonder why when a dog barks without any visible cause or when fowls quark unceasingly without birds or any other visible objects inducing them to do so, then the Igbos suspect that spirits may be around or that something mysterious is about to happen. Such behaviours by these animals are regarded as ominous signs. Apart from these general observations about the autonomous intrinsic values in animals, some selected animals in Igbo culture are believed to possess uncommon values that qualify them for sacrifices. Rainmakers in the Igbo cultural milieu value these animals much while making their sacrifices to bid a plea for rain.

Organisms: Let us, here, concern ourselves with plants among the other organisms because of its relevance to our study. Though not an inanimate object, like stone, a plant is not a subject as such. Plants demonstrate some interesting activities which are objectively intrinsic in them. For instance, we observe how plants repair their injuries when wounded how they conduct biological activities of photosynthesis and water-nutrient movements how they emit pheromones to attract insects for cross-pollination and allelopathic agents to ward off invaders howin grafting, they reject the incompatible other and accept the genetically same, etc. These and more are all value-qua-attribute in plants.

Plants, just like other species, occupy an important place in Igbo traditional philosophy. The Igbos nurse has a belief that spirits and deities inhabit some trees and grooves and as such consider them sacred. Besides, the roots, the herbs and the leaves of these plants are essential ingredients in the preparation of medicine and magical concoctions called Ogwu. Here, the rainmakers take the advantage of the endowments in a plant to cause the rain. Some leaves when gathered from the forest and burnt with some invocations to the gods or the ancestors, 


\section{J. Eng. Applied Sci., 14 (Special Issue 4): 7431-7436, 2019}

cause the rain to either fall or not to fall consequent upon the intention of the rainmaker. Therefore, plant is one of the special specie in the Igbo cultural environment that possesses the intrinsic values for assistance in the rainmaking technology.

Earth: Earlier, the challenge was to evaluate persons, animals and plants but environmental valuing is not over until, we have risen to the planetary level. In the words of Rolston (2010), "Earth is really the relevant survival unit. It is the only planet with an ecology. Earth may not be the only planet where anything is valuable-able to be valued by humans intrinsically or instrumentally-but it is the only place able to produce vitality before humans come." 5 Prior to man's arrival on Earth, the latter was already equipped with arsenals that aid life. The enabling environment for survival on Earth is not proceed from human ingenuity but a value already inhabiting the world before human arrival. Hence, it seems unfit to say that it is man's arrival on Earth that gave the Earth a credence for value. The Earth has intrinsic activities that aid life and that is why humans survive in it.

Rainmaking in the Igbo cultural technology: The Igbos constitute one of the three largest ethnic nationalities in Nigeria located in the Eastern part of the country. Their language is Igbo with many local dialects. In the words of Uwalaka (2003), "the Igbos as a people have a great historical and cultural pedigree as widely recognized and attested by world class anthropologists, colonial administrators and Foreign missionaries." Based on these qualities as observed by Uwalaka (2003), the Igbos have a very deep and rich cultural practices that aid their technologies, especially, in their appreciation and relational activities with their material and immaterial environments in rainmaking.

Rainmaking represents the sacred relationship between humans and the Divine. According to Iwu (2014), rain is viewed as a sacred and phenomenal gift from God, the most explicit expression of God's goodness, providence and love. Rainmakers represent the people's contact with the blessings of time and eternity, a link between humans and the Divine. The rainmakers do not rely exclusively on their spiritual powers, they are well versed in weather and environmental matters and may spend long periods of apprenticeship acquiring their knowledge. Subscribing to this view, ReShel (2017) submitted that, the ancient art of rainmaking was once practiced all around the world. It represented the sacred relationship between humans and the Divine. One very salient point about these rainmakers is that there is a kind of spiritual connection they create with their immediate environment when they want to make or mar rainfalls. ReShel (2017) opines that, "to understand these sacred traditions is to understand the extraordinary sacred connection indigenous people have with the land. That intuitive understanding and knowing about life, which gives them knowledge of where water is weather patterns, animal behavior and the messages nature is giving them." In Igbo culture, the rainmakers are considered to be rainmaking priests and priestesses and some Igbo tribes even have rainmaking clans. These groups in many occasions do conduct rituals. From inquiries, there are various ways through which the art of rainmaking is conducted in Igbo land. This might be different from what obtains in other places and cultures.

The tradition for evoking rain in some parts of Igbo land involves a ritual dance. These dances are passed down by an oral tradition. While these indigenous dances may look like ornate ceremonial practices, they are performed as potent rituals. The rain dance is performed to bring rain and growth to the land and the crops. When the land is dry and rain is needed for the plants, they dance and play instruments, so, they can wake up the god of fertility and rain. Also, in some areas, the native ways of influencing the weather for rain involves the use of leaves, shrubs and herbs. To this method, Adekunle discovered that, "we can use leaves, roots with some incantations to drive away the rain. If it is cloudy, once we match some leaves together and put it in a basin facing the direction where we want it to go, in few minutes, you will see the result and it will not rain." Adekunle further reported that "an anonymous rainmaker who refused to mention the leaves and shrubs used in clearing the weather said he could rig a thunderstorm out of a desert but he does not do it for a fee as it is against the interest of his gods insisting that he only does it to benefit his people."

Another rain-maker who denounced a mention of his name, said that "once he enters the bush and plucks some special leaves, stems and roots of plants, shrubs and grasses, he will combine and set them into flames and as soon as the smoke moves to the sky, the rain will start to fall." In a further interview with a graduate of geography from Ahmadu Bello University, Zaria, Adekunle reported him as saying that "the modern method uses a kind of stone called crystal stone." According to him, "the stone is washed and as soon as the stone starts glazing, the sky starts changing and soon rain starts". "He added that "the method is dangerous because it often attracts heavy thunderstorm."

Nnamene (2017) in his wild search certified that, "in Ekwulumili, Anambra State, rainmakers use stone, especially, mkpumeonu (a special kind of stone) to make 
rain." He further reported that, "In Nsukka area, some rainmakers claim to have inherited the art of rainmaking from their ancestors. In fact, one rainmaker says they use a certain type of plate with some quantity of sand, little water and cola nut which they would put at a strategic place and at a given time in the morning and on such day there would be rain. From our inquiries, "he concluded, "we discovered that there are some people who make and stop rains".

But there are those who do just one. They are either rainmakers or they are rain stoppers. Some rain stoppers, say if they weep under the rain, the rain stops. There are those who say they keep chanting incantations and the rain would stop.

From the above explanations, one thing persists namely, rainmaking involves man's relationship with his environment-both the material and the immaterial components. In one wing, the rainmakers as we saw above, report on how they use plants, animals, stones and other material species of the environment to arrive at their rainmaking technology. On the other wing of the art, we still observe the invocations, incantations, sacrifices and other ritual demonstrations which connect them to the powers unseen, the immaterial beings that aid in rainmaking technology. This justifies the expediency of the environmental species in assisting rainmaking practice in Igbo cultural environment. The Igbos make rain by their cordial relationship with their natural environment. It is based on the discovery the Igbos make about the intrinsic values in environmental species that assist them in manipulating the weather by the combination of these uncommon species designed for the purpose of rainmaking. The underlying element, here is that the intrinsic values in environmental species assist the Igbo cultural technologies, especially that of rainmaking.

Critical evaluation: In as much as one gets thrilled by the art of rainmaking in Igbo culture, there are much left to settle a curious observer. The selfishness of this art, ranging from the clandestine nature of the rainmakers to the family claims of the art, makes it impossible for a thorough investigation that can make the art more scientific. The testimony of a single individual or a single family or clan in such a salient art is not sufficient for any serious enterprise. It becomes unfortunate then to see some of those who possess these powers, go into extinction without a single document to hand over to the succeeding generations. This lack of documentation has crippled, so many claims about rainmaking in Igbo cultural technology. In defense of their selfish attitudes, most of these rainmakers claim that the gift is inherited from their ancestors and as such are not sharable. In their conclusions, they insist that even if they disclose the art to one who shares no lineage with them, it cannot function fruitfully. While this seems true in some cases, it is not true in all cases, especially, in such cases where an individual who is alien to a particular clan that claims to have the gift of rainmaking goes into apprenticeship of the art of rainmaking.

Also, it was established that animals, plants, stones, etc. (which are natural beings) are instrumental to the success of rainmaking in Igbo culture. One may then be moved to ask whether these natural beings were created to be of instrumental value to some people and not for all in the same environment. It beats the imagination that when one person handles a stone or a leaf, lightening and rain will come but the other will do same but call down neither lightening nor rain. Are there more than meets the eye in the practice or is nature partial in sharing value to the inhabitants of the same environment?

In another sense, though the Igbos manifest a strong link with their ancestors and respect them in spite of their invisible status, it disturbs any reasonable mind on why the gods, the ancestors and the deities must be consulted in the art of rainmaking when testimonies abound that a technical correlation of some leaves or roots can cause rain to either fall or not to fall. Why must there be sacrifices for what does not call for it? Nnamene (2017) said, "that in Igbo land, people attach, so much idol worshipping to rainmaking. To make or to stop rain, one would not need to be ritualistic or to be diabolic. Anything that precipitates the clouds would certainly make the rain and anything that disperses the clouds would certainly stop the rain. "However, it is pertinent to mention that people use different methods to make rain. Some people use leaves to make rain. Some other people use incantations. Some others use prayers". Therefore, it must not count as much necessity to offer a lot of sacrifices during the art of rainmaking. The gullible rainmakers use such media to extort money from their clients.

Finally, since, it has been discovered that some plants and animals including some inanimate substances possess some magical powers and assist in rainmaking, in the widest imagination could it not be possible that the Igbos generally and the rainmakers in particular are yet to make full discoveries of more instrumental and intrinsic values in other plants and animals around them, especially, those that are yet, to be considered sacred? Why some particular species and not all? Is it not a show of man's limited knowledge? Further research might expose us to further discoveries certainly and this will be necessary for the well-being of man. 


\section{CONCLUSION}

Man's relationship with his environment has a lot to offer him. Apart from the harvest of values intrinsic and instrumental in species, man maintains a cosmos that assists his development and sustains his life. The instrumental benefits notwithstanding, man has much to enjoy in the intrinsic values that in here in the environmental species. These double-winged values of his environment, help him in his discoveries and technologies. The Igbo cultural background displays this interest in the environment by attaching her technologies to it. Rainmaking for one is one of the most profound testimonies of how the Igbos relate with their environment. Other technologies abound which are not disconnected with the same assistance from the species in their environment. Hence, there is a harmony of relationship between the Igbos and their natural environment. Yet, we want to observe that beyond a mere correlation, the Igbos should dig further into a closer touch with their environment. It is lack of this closer touch that limits their knowledge into further discoveries of other values in most of the herbs, trees, leaves, roots and stones around them which may have more medicinal and magical powers than the ones already discovered. This involves what, we may call the principle of accommodation. Unlike anthropocentrism with its attendant discrimination, the principle of accommodation is all-embracing and reconciliatory. Accommodation has a considerable boundary within the capacities of an entity. These boundaries when respected and maintained, give room for functionality and a peaceful co-existence. Accommodation is guided by a moral law that establishes a mountain of respect between the subjects and the objects of an environment. If man (subject) is to create in his daily program, a space for the maintenance of his environment (object) and commits himself to it as a duty, he will discover more values in his environment. This is what the principle of accommodation indicates. By this principle, man will discover an eternal harvest in his environment.

\section{RECOMMENDATION}

There is the temptation of the exploitation of the environment by this art, if not guarded by some environmental laws. Man's zeal for consumerism may find a strong footing in a careless destruction of the environment in the name of rainmaking. Therefore, it is recommended that an orientation about the use of the environment should be made known to the apprentices of rainmaking. Also, those endowed with the gift of rainmaking should use it to assist the growth of human environment for sustainability not the destruction of nature and undue cause of pain to humanity.

\section{ACKNOWLEDGEMENT}

The researchers are grateful to Mr. B.C. Nwefuru for proofreading the initial draft of this study. We thank the reviewers for their comments that improved this study.

\section{REFERENCES}

Iwu, M.M., 2014. Handbook of African Medicinal Plants. 2nd Edn., CRC Press, UK., ISBN-13: 9781466571976 , Pages: 506.

Keller, D.R., 2010. Environmental Ethics: The Big Questions. Wiley-Blackwell, Hoboken, New Jersey, USA., ISBN:9781405176392, Pages: 600.

Njoku, F.O.C., 2006. Studies in Ethics. Clacom Publications, Lagos, Nigeria, Pages: 174.

Nnamene, E.C., 2017. Rainmaking. Catholic Diocese of Nsukka, Nigeria.

Norton, B.G., 1991. Toward Unity among Environmentalists. Oxford University Press, New York, USA., ISBN:9780195061123, Pages: 287.

Nwala, T.U., 1985. Igbo Philosophy: The Philosophy of the Igbo-Speaking Peoples of Nigeria. Lantern Books, Ikeja, Nigeria,.

ReShel, A., 2017. The ancient indigenous art of rainmaking. Uplift Publishing Company, Philadelphia, Pennsylvania. https://upliftconnect.com/ancientindigenous-rainmaking/

Rolston, H., 2010. Value in Nature and the Nature of Value. In: Environmental Ethics: The Big Questions, Keller, D.R. (Ed.). Wiley-Blackwell, Hoboken, New Jersey, USA., ISBN:9781405176392, pp: 130-137.

Uwalaka, J.N., 2003. The Struggle for an Inclusive Nigeria: Igbos, to be or Not to be? A Treatise on Igbo Political Personality and Survival in Nigeria. Snaap Press, Enugu, Nigeria, ISBN:9789780492809, Pages: 232. 